\title{
La infección genital por Chlamydia trachomatis estaría asociada con el desarrollo de cáncer de cuello uterino
}

Serotypes of chlamydia trachomatis and risk for development of cervical carcinoma. Tarje Antiklla, Pekka Saiku, Penti Koskela, et al. JAMA 2001 Jan 285:47-51.

\section{Objetivo}

Evaluar si existe asociación entre los diferentes serotipos de Chlamydia trachomatis (CT) y el desarrollo del cáncer de cuello uterino $(\mathrm{CCU})$.

\section{Diseño}

Estudio caso-control anidado* a partir de una cohorte de 530000 mujeres de muestras de bancos de sangre de países nórdicos.

\section{Lugar}

Se realizó en Finlandia, Suecia y Noruega.

\section{Participantes}

Participaron en este trabajo 128 mujeres con CCU invasivo desarrollado por lo menos 12 meses luego de la donación de sangre y se seleccionaron tres controles de la misma población (banco de sangre) para cada caso. Los casos fueron obtenidos a partir del registro nacional de cáncer de los países mencionados.

\section{Evaluación de factores de riesgo}

Se evaluó la exposición a diferentes serotipos de CT, infección por papillomavirus humano (HPV tipos 16,18 y 33) y tabaquismo.

\section{Medición de resultados principales}

Se midió lg G para serotipos específicos de CT por dos métodos diferentes (microinmunoensayo y cuerpo elemental), cotinina sérica (como indicador de tabaquismo) y serología ( $\lg G$ ) para los tipos 16,18 y 33 de HPV.

\section{Resultados principales}

Se observó asociación de CCU con infección por CT independiente del tabaquismo y de la infección por HPV. Todos los serotipos estudiados se asociaron al CCU. El serotipo G tuvo un OR 6.6 (IC 95\% 1.6-27), el serotipo I OR 3.8 (IC 95\% 1.3-11) y el D, un OR 2.7 (1.3-5.6). Por otro lado, la presencia de más de un serotipo diferente aumentaba la fuerza de la asociación con una tendencia estadísticamente significativa $(p=0.0001)$.

\section{Conclusiones}

La infección de CT se asoció al desarrollo de CCU. Entre los diferentes serotipos de $\mathrm{CT}$, la infección con el tipo G parece estar más fuerternente asociado con el desarrollo de CCU.

\section{Comentario}

El comportamiento del CCU es bastante conocido, la incidencia del cáncer invasivo comienza a incrementarse desde los 35 años de edad hasta los 39 años y alcanza una meseta de 20 por 100.000; mientras que la incidencia del CCU in situ es más alta (130 por 100.000), ocurre entre los 25 y 35 años y luego declina hacia los 50 años (20 por1.000.000). Los factores de riesgo del CCU identificados hasta el momento abarcan el tabaquismo, el inicio temprano de relaciones sexuales, el número de parejas sexuales, los antecedentes de enfermedades transmisión sexual, y es dos veces más frecuente en mujeres de color o hispánicas que en blancas 1

Por otro lado sabemos que en la actualidad la infección por CT es la enfermedad de transmisión sexual que se reporta con mayor frecuencia en EE.UU. y su incidencia ha aumentado en los últimos años (182 casos por 100000 en 1995 á 197 por 100.000 en 1997), lo que en dicho país se traduce en más de 4 mịllones anuales. Esta infección tiene particular repercusión entre las mujeres por sus posibles secuelas o complicaciones (enfermedad inflamatoria pelviana, embarazo ectópico e infertilidad tubaria)². La forma asintomática es tres veces más frecuente que la manifiesta clínicamente, y su prevalencia es muy variable con reportes que oscilan entre un 3\% a más del $20 \%$ según la población en la cual ha sido analizada ${ }^{3}$. Dentro de las enfermedades de transmisión sexual, la relación entre infección por HPV y CCU es una de las más estudiadas, se ha establecido su asociación y disponemos de datos en Latinoamérica ${ }^{4}$, no así respecto a la infección por CT, y en este punto los hallazgos por el momento no son consistentes. Los trabajos en general están basados en población de alto riesgo, son retrospectivos ${ }^{*}{ }^{*}$ o caso control como el aquí resumido, con la posible inclusión de sesgos o presencia de variables confundidoras* no conocidos y que este tipo de diseño no permite controlar. Este trabajo surgió a partir de un estudio de cohorte ${ }^{*}$ finlandés ${ }^{6}$ en el que se observó asociación de CCU con CT ajustado por infección de HPV y tabaquismo. No obstante, con la evidencia disponible por el momento, y recordando los criterios de Bradford Hill de causalidad (temporalidad, fuerza de asociación, dosis respuesta, reversibilidad, consistencia, plausibilidad biológica, especificidad y analogía) se plantea la necesidad de continuar estudiando esta asociación. De confirmarse estos hallazgos, le otorgaría más fuerza a las recomendaciones actuales sobre realizar el rastreo de esta infección en población de riesgo según la prevalencia de cada región.

6. Koskela P; Anttila T; Bjorge T y col. Chlamydia trachomatis infection as a risk factor for invasive cervical cancer. Int J Cancer, 2000; 85 (1):35-39. 